\title{
Influence of Characteristics of Thermoplastic Polyurethane on Graphene-Thermoplastic Polyurethane Composite Film
}

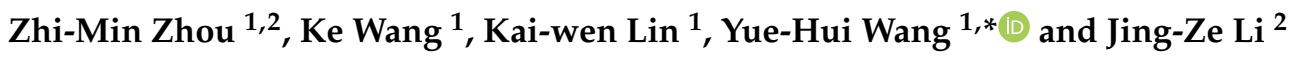 \\ 1 Department of Materials and Food, Zhongshan Institute, University of Electronic Science and Technology of \\ China, Zhongshan 528402, China; zzmzsedu@126.com (Z.-M.Z.); wkzsedu@126.com (K.W.); \\ kevinlin1990@163.com (K.-w.L.) \\ 2 Department of Material and Energy, University of Electronic Science and Technology of China, \\ Chengdu 610054, China; lijingze@uestc.edu.cn \\ * Correspondence: wangzsedu@126.com; Tel.: +86-15-900-020-061
}

Citation: Zhou, Z.-M.; Wang, K.; Lin, K.-w.; Wang, Y.-H.; Li, J.-Z. Influence of Characteristics of Thermoplastic Polyurethane on GrapheneThermoplastic Polyurethane Composite Film. Micromachines 2021, 12, 129. https://doi.org/10.3390/ mi12020129

Received: 20 December 2020

Accepted: 24 January 2021

Published: 26 January 2021

Publisher's Note: MDPI stays neutral with regard to jurisdictional claims in published maps and institutional affiliations.

Copyright: (c) 2021 by the authors. Licensee MDPI, Basel, Switzerland. This article is an open access article distributed under the terms and conditions of the Creative Commons Attribution (CC BY) license (https:// creativecommons.org/licenses/by/ $4.0 /)$.

\begin{abstract}
Graphene-thermoplastic polyurethane (G-TPU) composite films were fabricated by traditional blending method and tape casting process with commercial graphene sheets as functional fillers and TPU masterbatches of four different melting points as matrix, respectively. The effects of matrix on the distribution of graphene, the electrical conductivity, and infrared (IR) light thermal properties of the G-TPU composite films were investigated. The experimental results reveal that the characteristics of TPU has little influence on the electrical conductivity of the G-TPU composite films, although the four TPU solutions have different viscosities. However, under the same graphene mass content, the thermal conductivity of four G-TPU composite films with different melting points is significantly different. The four kinds of G-TPU composite films have obvious infrared (IR) thermal effect. There is little difference in the temperatures between the composite films prepared by TPU with melting a point of $100{ }^{\circ} \mathrm{C}, 120^{\circ} \mathrm{C}$, and $140{ }^{\circ} \mathrm{C}$, respectively; however, when the content of graphene is less than $5 \mathrm{wt} \%$, the temperature of the composite film prepared by TPU with a melting point of $163{ }^{\circ} \mathrm{C}$ is obviously lower than that of the other three composite films. The possible reason for this phenomenon is related to the structure of TPU.
\end{abstract}

Keywords: graphene; thermoplastic polyurethane; near-infrared photothermal response; film

\section{Introduction}

In recent years, with the development of electronics, communication, and artificial intelligence industry, flexible conductive composites have attracted extensive attention in academia and industry due to its portability, good biological compatibility, and stretchability and are widely used in sensors, flexible displays, energy devices, medical electronics and integrated circuit, and so on [1-5]. At present, flexible conductive composite materials are usually composed of polymer materials and conductive nanomaterials [4-8]. Polymer materials, such as epoxy, polyimide, and polyurethane, as flexible substrates are mostly insulators and do not have electrical conductivity. Conductive nanomaterials generally include graphene and its derivatives [6-9], carbon nanotubes [10], metal nanowires [11] and their derivatives [12]. Adding conductive nanomaterials into the matrix or surface of polymer materials can not only solve the shortcomings of the polymer itself, such as brittleness, poor electrical conductivity and thermal conductivity, but also use the special properties of nanomaterials to broaden the application fields of polymer materials [7,13-16].

Polyurethane is a kind of block polymer composed of hard and soft segments, which has high industrial value and research value due to its excellent oil resistance, abrasion resistance, stretchability and so on [17]. Thermoplastic polyurethane (TPU), as an important branch of polyurethane, shows potential for use in the preparation of perforated membrane because of its excellent tensility, good elastic resilience, and excellent biocompat- 
ibility [18-21]. However, due to its poor electrical conductivity and thermal conductivity, it is difficult to further expand its application fields [19,22].

Graphene $(\mathrm{G})$, a novel two-dimensional honeycomb carbon nanomaterial, has large specific surface area and excellent mechanical, optical, thermal and electrical properties, and also has excellent energy conversion capabilities, such as photothermal conversion, electrothermal conversion, and magnetothermal conversion, is a kind of promising nanomaterial $[15,21,23,24]$. Therefore, graphene as functional fillers were widely used in to prepare functional materials. Li et al. reported a novel self-healing electronic material with a three-dimensional graphene structure based on Diels-Alders chemistry [1]. Oh et al. reported that they used graphene nanoplates as reinforcing agents and crosslinking platform to react with the furfuryl functional groups in the polyurethane chain via in situ Diels-Alders reaction and synthesized thermally self-healable graphene-nanoplatespolyurethane (GNP-PU) composites [6]. Wang et al. reported that they prepared thermally and mechanically reinforced graphene-thermoplastic polyurethane composites by solution mixing [9]. Luan et al. reported that they filled graphene and carbon nanotubes into TPU to synthesize composites that can be repaired under microwave radiation [20]. Huang et al. reported that they added few-layers graphene into TPU to prepare functional materials that can be healed by microwave, near-infrared light, and electricity [21]. Chen et al. reported that they prepared stretchable and conductive G-TPU nanocomposite foam materials via water vapor induced phase separation technology [18]. Strankowski et al. reported that they used graphene nanoplates and reduced graphene oxide as fillers to prepare two kind of thermally reinforced and mechanically reinforced TPU composites [25]. Cataldi et al. reported that they prepared self-healing flexible conductive cotton textiles by impregnating cotton fabrics in graphene and thermoplastic polyurethane-based dispersions [26]. Roy et al. reported that they prepared mechanically and thermally enhanced composites by incorporating multi-walled carbon nanotubes and graphene hybrid systems into thermoplastic polyurethane [27].

However, most of the previous studies only focused on the mechanical, thermal, and electrical properties of G-TPU composites, while ignoring the electro-thermal and photothermal conversion capabilities of G-TPU composites $[1,6,8,9,24-26,28,29]$. We have reported that the electrical and thermal and self-healing properties of G-TPU conductive film were closely related to the mass content of graphene in the G-TPU film, while the infrared light thermal response performance of G-TPU film has nothing to do with the mass content of graphene in the G-TPU film [25]. In this paper, we fabricated the GTPU composite films via traditional blending method and tape casting process, then we systematically investigated the effects of the characteristics of TPU on the near-infrared photo-thermal response of G-TPU composite film.

\section{Materials and Methods}

\subsection{Materials}

Graphenesheets ( $\mathrm{G}>98 \mathrm{wt} \%$ ) with less than 3 layers and an average particle size less than $10 \mu \mathrm{m}$ were purchased from Chengdu Jiacai Technology Co., Ltd., Chengdu, China. $\mathrm{N}, \mathrm{N}$-Dimethylformamide (DMF) was purchased from Guangzhou Chemical Reagent Co., Ltd., Guangzhou, China; thermoplastic polyurethane (TPU) masterbatches model number: HF-3H85A-3 (TPU-A), HM85A (TPU-B), and E685C4 (TPU-C), respectively, were purchased from BASF (China) Company Ltd. Guangzhou Branch, Guangzhou, China; ALR CL87A (TPU-D) masterbatches were purchased from Lubrizol Estane Chemical Co. Ltd., Estane Lubrizol, Cleveland, OH, USA. 


\subsection{Methods}

\subsubsection{Preparation of G-TPU Composite Film}

Typical preparation processes are described as follows: $16 \mathrm{~g}$ TPU masterbatches were added into $80 \mathrm{~mL}$ DMF, followed by ultrasound and stirring with a stirring rod until completely dissolved. The $0.6 \mathrm{~g}$ graphene sheets were added into a flask containing DMF solution under vigorous stirring and ultrasound for $30 \mathrm{~min}$. Then, the TPU solution was added into the above graphene DMF under vigorous agitation and the G-TPU solution was dispersed at $3500 \mathrm{rpm} / \mathrm{min}$ for $60 \mathrm{~min}$ by a high-speed shear disperser. Finally, the G-TPU solution was poured into the Teflon mold and dried at $70{ }^{\circ} \mathrm{C}$ until the weight did not change any more, then the G-TPU composite film were obtained. The G-TPU composite film was peeled off for further testing. G-TPU compound films with different properties were obtained by changing the type of TPU and the mass content of GP. Figure 1 shows a schematic diagram of the fabrication process of G-TPU composite film.

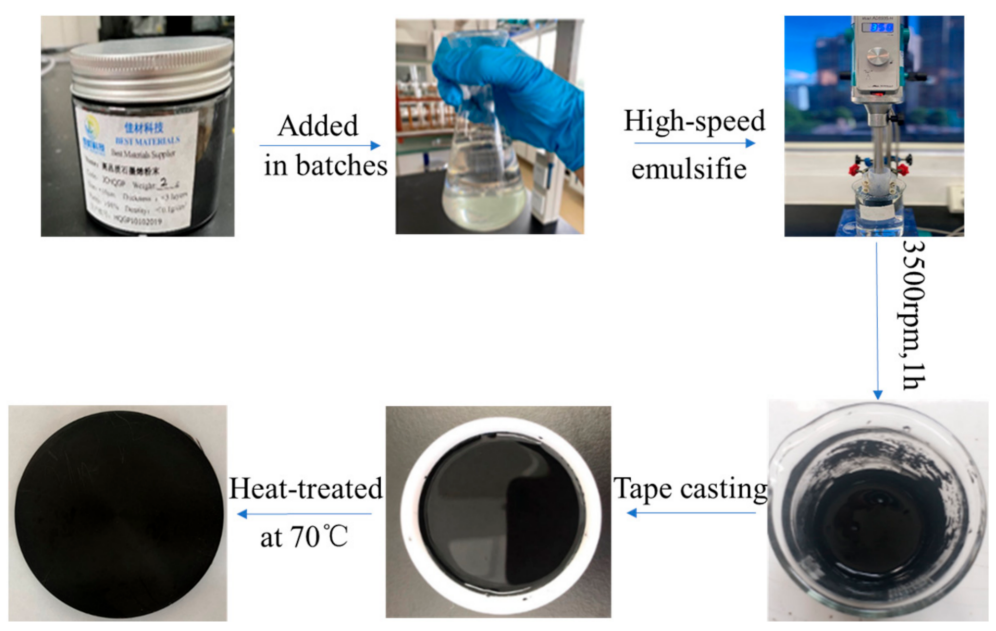

Figure 1. Schematic diagram of the fabrication process of G-TPU composite film.

\subsubsection{Characterization}

Differential scanning calorimetry (DSC) analysis was conducted via simultaneous differential thermal analysis (TA Q2000 V24.1 Build 124, NETZSCH-Gertebau GmbH, Selb, Germany). The weight of sample was $13-15 \mathrm{mg}$, Gas1: Nitrogen $50.0 \mathrm{~mL} \cdot \mathrm{min}^{-1}$, the heating rate was $20^{\circ} \mathrm{C} / \mathrm{min}$, and the sample test was heated from $-80^{\circ} \mathrm{C}$ to $200{ }^{\circ} \mathrm{C}$, then naturally cooled to $-80^{\circ} \mathrm{C}$, and then heated to $200^{\circ} \mathrm{C}$. The curves in the figure showed the temperature rise from $-80^{\circ} \mathrm{C}$ to $200^{\circ} \mathrm{C}$ after removing the thermal stress. Scanning electron microscope (SEM, Zeiss sigma 500, Carl Zeiss, Germany), and optical microscope (Nikon LV100, Nikon Co., Ltd., Tokyo, Japan) with a digital camera were used to investigate the microstructure of G-TPU flexible conductive film. The resistance was measured by a four-point probe system (ST2253, Suzhou Jingge Electronics Co., Ltd. Suzhou, China). The resistances of each sample were each measured at twenty different sites and calculated from the average value of those measurements. An infrared thermal imager (UTI384M, range: $-20-150{ }^{\circ} \mathrm{C}$, accuracy: $\pm 2{ }^{\circ} \mathrm{C}$, UNI-T China Co., Ltd., Shenzhen, Guangdong, China) was used. The thermal conductivity of sample was measured by a DRL-III heat flow meter instrument (Xiangtan Xiangyi Instrument Co. Ltd., Xiangtan, China) according to the standard ASTM D5470. 


\section{Results and Discussion}

\subsection{Electrical Property of G-TPU Flexible Conductive Film}

TPU is a copolymer consisting of both hard and soft segments. Its properties are mainly determined by the monomers, such as the type and crystallinity and copolymer morphologies of hard and soft segments [19-21]. The hard section has a direct effect on the mechanical properties of TPU, such as tensile strength, hardness, and modulus; the soft segment determines the elasticity and low temperature resistance of the TPU. Previous studies have shown that graphene can not only strengthen and toughen TPU, but also improve the properties of TPU, such as wear resistance, scratch resistance, heat resistance, aging resistance, electromagnetic shielding property, etc. $[6,9,20-27]$. The distribution of graphene sheets in TPU and their binding state affect the curing behavior of TPU, which affects electrical and thermal properties and microstructures of the composite films [20-23]. According to our previous research, the electrical and thermal and infrared light properties of G-TPU composite films are related not only to the mass content of graphene, but also to the initial TPU concentration [25,26]. The initial TPU concentration of $20 \mathrm{wt} \%$ is beneficial to obtain the G-TPU composite film with good electrical and thermal properties $[25,26]$. Here, TPU with the initial concentration of $20 \mathrm{wt} \%$ is used to combine graphene with different mass contents. TPU with four different melting points $\left(110^{\circ} \mathrm{C}, 120^{\circ} \mathrm{C}, 140{ }^{\circ} \mathrm{C}\right.$, and $163^{\circ} \mathrm{C}$, respectively) were used to study the influence of the characteristics of TPU on the electrical and thermal and infrared light properties of G-TPU composite films.

Figure 2 shows the relationship between the resistivity of the conductive films composed of four different melting points of TPU and the graphene mass content, respectively. The inset in Figure 2 is photo of light emitting diode device on the G-TPU conductive film. The G-TPU composite films composed of four different melting points of TPU, respectively, were not conductive when the graphene mass content is less than $3 \mathrm{wt} \%$. When the graphene mass content reached $3 \mathrm{wt} \%$, the composite films began to be conductive, but it is clear that the conductivities of composite films have little to do with the characteristics of TPU. We believe that the slight difference in resistivity between different samples is related to the measurement error. When the graphene mass contents reached $3 \mathrm{wt} \%, 4 \mathrm{wt} \%, 5 \mathrm{wt} \%$, and $7 \mathrm{wt} \%$, the resistivity of G-TPU flexible conductive films was about $90.0 \Omega \cdot \mathrm{m}, 3.0 \Omega \cdot \mathrm{m}$, $1.1 \Omega \cdot \mathrm{m}$, and $0.02 \Omega \cdot \mathrm{m}$, respectively. During heat treatment process of samples, the TPU molecular chains began crosslinking as the DMF volatilized and the mixed slurry gradually became a thin film. With the extension of heat treatment time, the film gradually shrank, making the graphene sheets overlap and stack to form conductive networks. When the mass content of graphene was low (less than $3 \mathrm{wt} \%$ ), the effective conducting networks could not be formed, so the composite film was non-conductive. When the mass content of graphene reached $3 \mathrm{wt} \%$, a part of the effective conductive pathways were formed, and the flexible conductive film exhibited electrical conductivity, but the resistivity was still high. This indicates that the conductive mechanism of G-TPU composite conductive film conforms to the percolation threshold theory. When the number of graphene sheets overlapping is up to threshold, a considerable ensemble of electrons is finally transported in the entire graphene sheets networks. As the graphene mass content further increases, the number of conductive pathways increases and form more conductive networks, so that the resistivity of G-TPU films gradually decreases until it is stable. The experimental results in Figure 2 show that the distribution of graphene in TPU with different characteristics are not affected by the characteristics of TPU matrix, or it can be said that graphene sheets have similar effects on curing behaviors of TPU. A photo of a light-emitting diode device on the G-TPU film proves good electrical conductivity. 


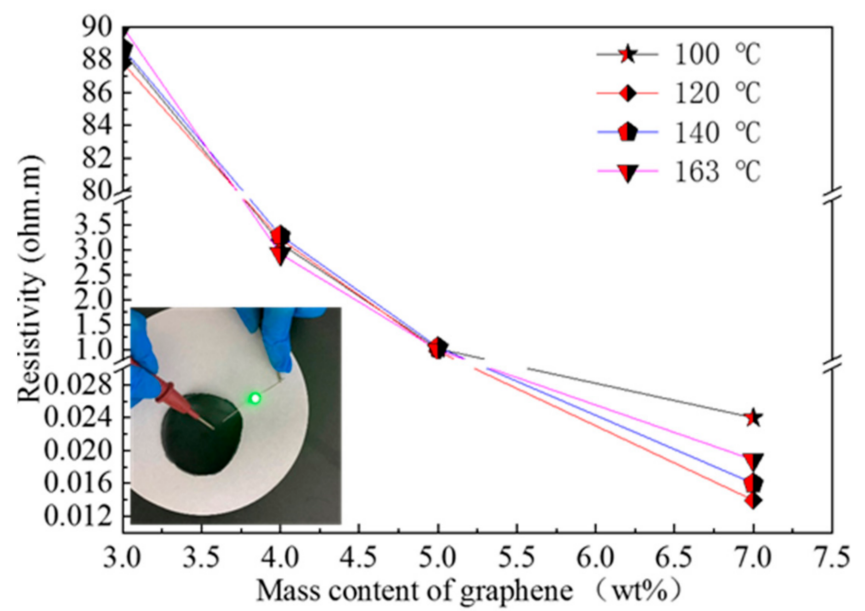

Figure 2. Relationship between the resistivity of the conductive films composed of four different melting points of TPU and the graphene mass content, respectively. The insert is photo of light emitting diode device on the G-TPU conductive film.

Figure 3 shows photos of samples of the pure TPU film (melt point of $163{ }^{\circ} \mathrm{C}$, Figure 3a) and G-TPU composite films with graphene mass content of $0.1 \mathrm{wt} \%$ (Figure $3 \mathrm{~b}$ ), $0.3 \mathrm{wt} \%$ (Figure 3c), $0.6 \mathrm{wt} \%$ (Figure 3d), $1.0 \mathrm{wt} \%$ (Figure 3e), $2.0 \mathrm{wt} \%$ (Figure 3f), 3.0 wt\% (Figure 3g), $4.0 \mathrm{wt} \%$ (Figure $3 \mathrm{~h}$ ), $5.0 \mathrm{wt} \%$ (Figure $3 \mathrm{i}$ ), and $7.0 \mathrm{wt} \%$ (Figure $3 \mathrm{j}$ ), respectively. When the graphene mass content is less than $0.6 \mathrm{wt} \%$, the composite film is translucent, after that the composite films become opaque black.

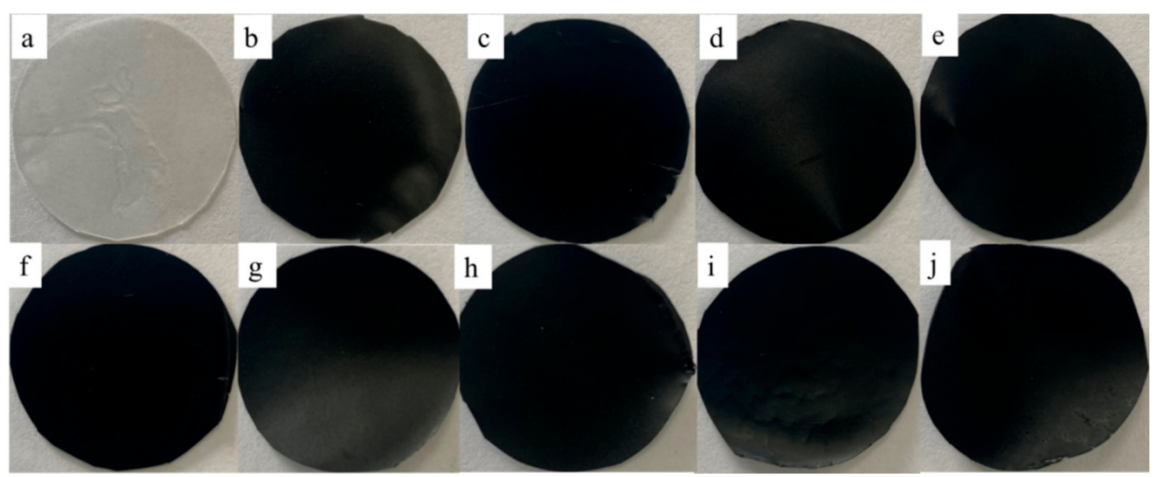

Figure 3. Photos of samples of pure TPU film (melt point of $163^{\circ} \mathrm{C},(\mathbf{a})$ ), and G-TPU composite films with graphene mass content of $0.1 \mathrm{wt} \%(\mathbf{b}), 0.3 \mathrm{wt} \%(\mathbf{c}), 0.6 \mathrm{wt} \%(\mathbf{d}), 1.0 \mathrm{wt} \%(\mathbf{e}), 2.0 \mathrm{wt} \%(\mathbf{f}), 3.0 \mathrm{wt} \%$ $(\mathrm{g}), 4.0 \mathrm{wt} \%(\mathbf{h}), 5.0 \mathrm{wt} \%(\mathbf{i})$, and $7.0 \mathrm{wt} \%(\mathbf{j})$, respectively.

In order to understand the distribution of graphene in TPU, the samples were conducted by SEM. Figure 4 shows SEM images of surface morphology of the composite films prepared with TPU (melt point of $163{ }^{\circ} \mathrm{C}$ ) and the graphene mass content of of $0.3 \mathrm{wt} \%$ (Figure $4 \mathrm{a}$ ), $0.6 \mathrm{wt} \%$ (Figure $4 \mathrm{~b}$ ), $2.0 \mathrm{wt} \%$ (Figure $4 \mathrm{c}$ ), $3.0 \mathrm{wt} \%$ (Figure $4 \mathrm{~d}$ ), 4.0 $\mathrm{wt} \%$ (Figure $4 \mathrm{e}$ ), $5.0 \mathrm{wt} \%$ (Figure $4 \mathrm{f}$ ), and $7.0 \mathrm{wt} \%$ (Figure $4 \mathrm{~g}$ ), respectively. It can be seen from Figure 4 that when the graphene mass content is less than $3 \mathrm{wt} \%$, the TPU strips and individual graphene blocks (red dotted area) are found on the surface of the G-TPU film. When the graphene mass contents reach $3 \mathrm{wt} \%$ and $4 \mathrm{wt} \%$, the surfaces of the G-TPU films are obviously roughened and have many particle-like agglomerates, while the surfaces look dense. When the graphene mass contents reach $5 \mathrm{wt} \%$ and $7 \mathrm{wt} \%$, more particle-like aggregates are observed and there are many holes between the aggregates, indicating that, due to the insufficient amount of TPU, the gaps between the aggregates are not filled well. Obviously, as the graphene mass content increases, the more graphene sheets overlap with each other, and the more conductive pathways and networks are formed. However, the 
excessive graphene mass content leads to severe agglomeration of graphene sheets, which leads to the existence of many holes in the composite film.
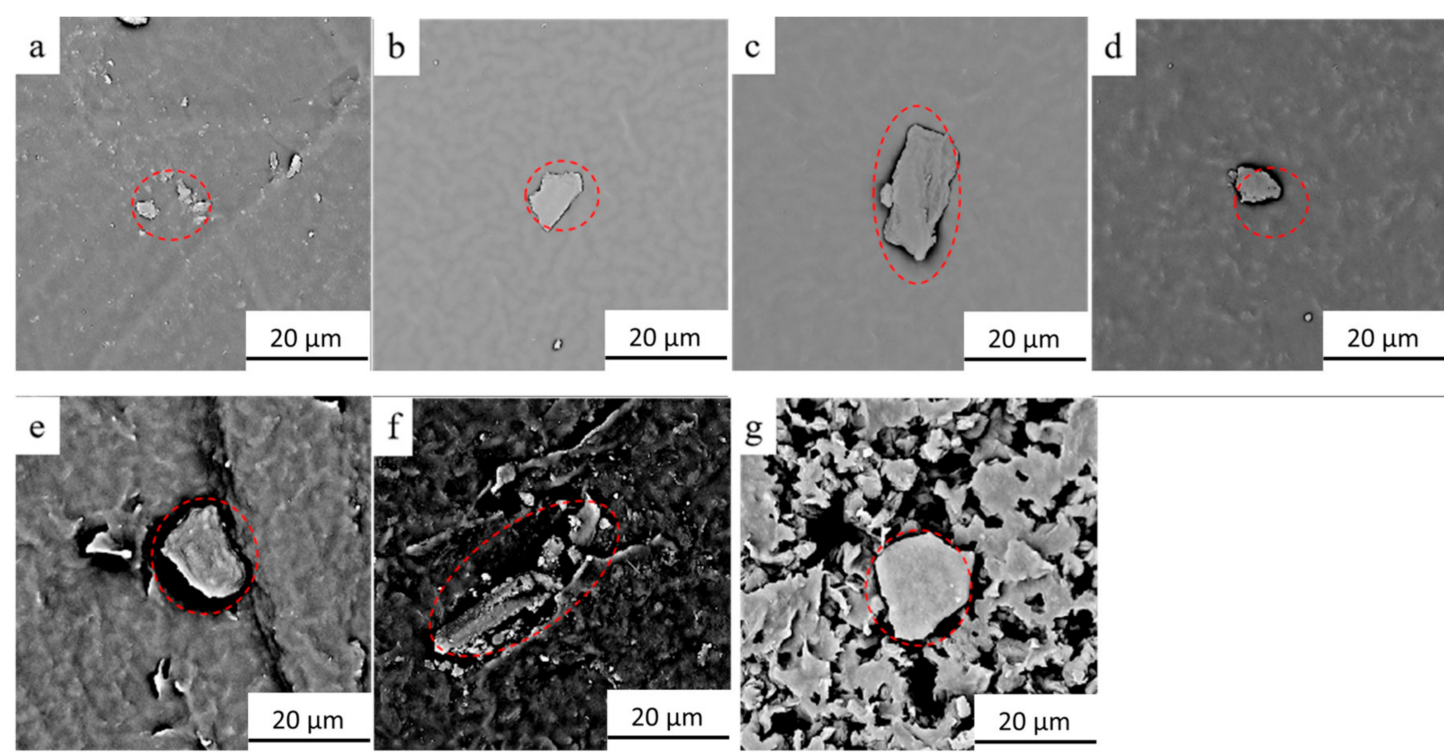

Figure 4. SEM images of surface morphology of the composite films prepared with the initial TPU concentration of $20 \mathrm{wt} \%$ and the graphene mass content of $0.3 \mathrm{wt} \%(\mathbf{a}), 0.6 \mathrm{wt} \%(\mathbf{b}), 2.0 \mathrm{wt} \%(\mathbf{c}), 3.0 \mathrm{wt} \%(\mathbf{d}), 4.0 \mathrm{wt} \%(\mathbf{e}), 5.0 \mathrm{wt} \%(\mathbf{f})$, and $7.0 \mathrm{wt} \%(\mathbf{g})$, respectively.

Figure 5 shows SEM images of the top section (above) and cross-section (below) morphologies of the G-TPU films prepared from TPU with melting points of $100{ }^{\circ} \mathrm{C}$ (Figure 5a,b), $120^{\circ} \mathrm{C}$ (Figure 5c,d), $140{ }^{\circ} \mathrm{C}$ (Figure 5e,f), $163^{\circ} \mathrm{C}$ (Figure 5g,h), respectively, and the graphene mass content of $4 \mathrm{wt} \%$. The graphene sheets overlapped in the TPU matrix can been observed and there is no significant difference in the distribution of graphene sheets among the four kinds of TPU.
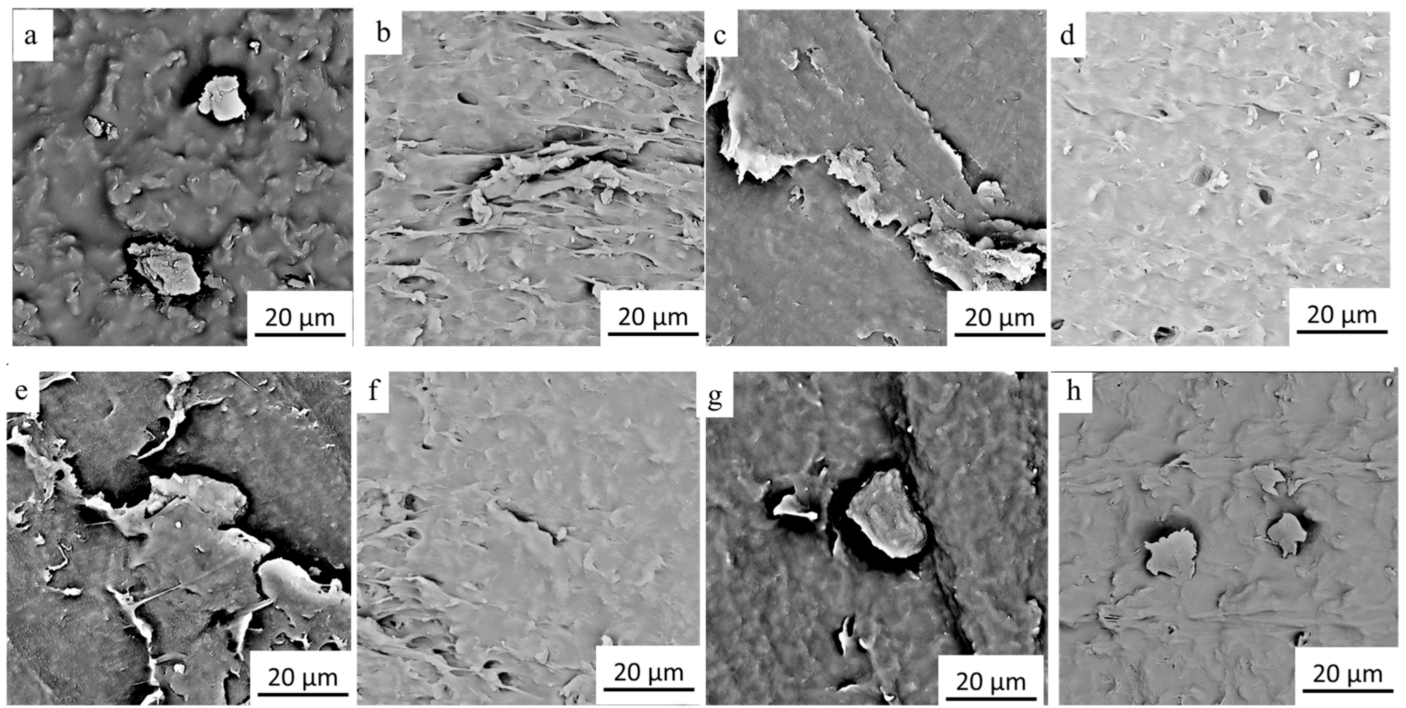

Figure 5. SEM images of top section (above) and cross-section (below) morphologies of the G-TPU films prepared from TPU with melting points of $100{ }^{\circ} \mathrm{C}(\mathbf{a}, \mathbf{b}), 120^{\circ} \mathrm{C}(\mathbf{c}, \mathbf{d}), 140{ }^{\circ} \mathrm{C}(\mathbf{e}, \mathbf{f}), 163{ }^{\circ} \mathrm{C}(\mathbf{g}, \mathbf{h})$, respectively, and the graphene mass content of $4 \mathrm{wt} \%$. 


\subsection{Thermal Property of G-TPU Composite Film}

Figure 6 shows the DSC measurements of G-TPU composite films prepared from TPU with melting points of $163^{\circ} \mathrm{C}$ and the graphene with different mass contents (Figure 6a) and G-TPU composite films prepared from TPU with the melting point of $100^{\circ} \mathrm{C}$ (Figure $6 \mathrm{~b}$, curve $\left.a, a^{\prime}\right), 120^{\circ} \mathrm{C}$ (Figure $6 b$, curve $b, b^{\prime}$ ), and $140^{\circ} \mathrm{C}$ (Figure $6 \mathrm{~b}$, curve c, $c^{\prime}$ ), respectively, and the graphene mass content of $4 \mathrm{wt} \%$ (Figure 6b). Seen from curve a in Figure 6a, two melting peaks of about $-35^{\circ} \mathrm{C}$ and $163{ }^{\circ} \mathrm{C}$ were observed in the curve a, which are related to glass-transition temperature $\left(\mathrm{T}_{\mathrm{g}}\right)$ and the melt $\left(\mathrm{T}_{\mathrm{m}}\right)$ that occurs in the soft segment and hard segment micro-crystalline area, respectively. With the increase of the graphene in the G-TPU, both the glass-transition temperature and the melting point of TPU are almost constant, but the $\Delta \mathrm{H}_{\mathrm{m}}$ increases, indicating that the graphene affects the curing behavior of TPU and facilitates the molecular chain movement. However, the degree of influence on the molecular chain movement is small, not enough to make the yield point temperature change when the polyurethane material is heated. As seen from Figure $6 \mathrm{~b}$, comparing to the pure TPU films with different melting points, the glass-transition temperature and the melting point of the G-TPU composite films composed of the TPU with different melting points do not have an obvious difference. The above experimental results indicate that the graphene has a certain effect on the curing behavior of polyurethane, i.e., the motion of soft and hard segments, but does not affect the properties of soft and hard segments.
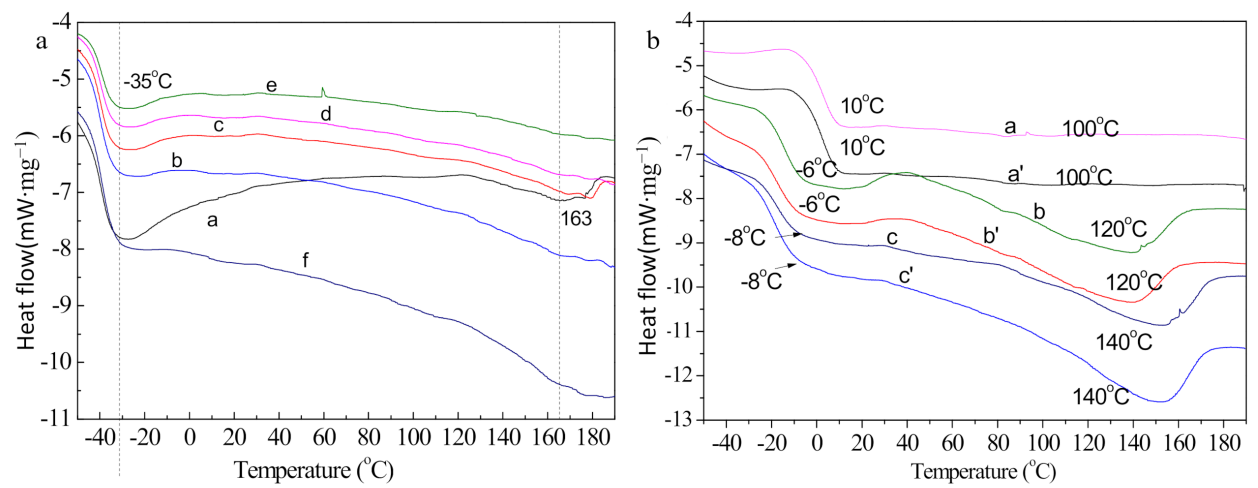

Figure 6. DSC measurements of G-TPU composite films prepared from TPU with melting points of $163{ }^{\circ} \mathrm{C}$ and the graphene with different mass contents (Figure 6a) and G-TPU composite films prepared from TPU with the melting point of $100{ }^{\circ} \mathrm{C}$ (Figure $6 \mathrm{~b}$, curve $\mathrm{a}, \mathrm{a}^{\prime}$ ), $120^{\circ} \mathrm{C}$ (Figure $6 \mathrm{~b}$, curve $\left.\mathrm{b}, \mathrm{b}^{\prime}\right), 140^{\circ} \mathrm{C}$ (Figure $6 \mathrm{~b}$, curve $\mathrm{c}, \mathrm{c}^{\prime}$ ), respectively, and the graphene mass content of $4 \mathrm{wt} \%$ (Figure $6 \mathrm{~b}$ ).

Figure 7 shows the relationship between the mass content of graphene in the G-TPU film and the thermal conductivities of the pure TPU and the G-TPU composite films with the melting point TPU of being $100^{\circ} \mathrm{C}, 120^{\circ} \mathrm{C}, 140{ }^{\circ} \mathrm{C}$, and $163^{\circ} \mathrm{C}$, respectively. The thermal conductivities of the pure TPU with the melting point of TPU at $100{ }^{\circ} \mathrm{C}, 120^{\circ} \mathrm{C}, 140{ }^{\circ} \mathrm{C}$, and $163{ }^{\circ} \mathrm{C}$, respectively, are $0.2137 \mathrm{~W} \cdot \mathrm{m}^{-1} \cdot \mathrm{K}^{-1}, 0.231 \mathrm{~W} \cdot \mathrm{m}^{-1} \cdot \mathrm{K}^{-1}, 0.2123 \mathrm{~W} \cdot \mathrm{m}^{-1} \cdot \mathrm{K}^{-1}$, and $0.2158 \mathrm{~W} \cdot \mathrm{m}^{-1} \cdot \mathrm{K}^{-1}$, respectively. The thermal conductivities of the G-TPU composite films with the melting point of TPU at $100{ }^{\circ} \mathrm{C}, 120^{\circ} \mathrm{C}, 140{ }^{\circ} \mathrm{C}$, and $163^{\circ} \mathrm{C}$, respectively, first increase and then decrease with the increases of the mass content of graphene in G-TPU film and when the graphene mass content in G-TPU film is $4 \mathrm{wt} \%$, and the thermal conductivity of the G-TPU film reaches the maximum, which are $0.4365 \mathrm{~W} \cdot \mathrm{m}^{-1} \cdot \mathrm{K}^{-1}$, $0.4706 \mathrm{~W} \cdot \mathrm{m}^{-1} \cdot \mathrm{K}^{-1}, 0.5434 \mathrm{~W} \cdot \mathrm{m}^{-1} \cdot \mathrm{K}^{-1}$, and $0.3657 \mathrm{~W} \cdot \mathrm{m}^{-1} \cdot \mathrm{K}^{-1}$, increasing by a factor of $2.04,2.04,2.56,1.69$, respectively. As mentioned above, when the graphene content in the composite film is lower than $4 \mathrm{wt} \%$, the graphene sheets overlap and stack to form thermal conductive pathways. As the graphene mass content in the G-TPU film increases to $4 \mathrm{wt} \%$, the graphene sheets show an obvious agglomeration phenomenon, and then a large number of thermal conductive pathways are destroyed [26], and the thermal conductivity of the G-TPU film decreases. 
It is worth noting that the thermal conductivity of the G-TPU films prepared from the TPU with different melting points was significantly different from the variation of their conductivity (as shown in Figure 2). The thermal conductivities of the G-TPU films are as follows: $\mathrm{K}_{\mathrm{G}-\mathrm{TPU}}\left(120^{\circ} \mathrm{C}\right)>\mathrm{K}_{\mathrm{G}-\mathrm{TPU}}\left(100^{\circ} \mathrm{C}\right)>\mathrm{K}_{\mathrm{G}-\mathrm{TPU}}\left(140^{\circ} \mathrm{C}\right)>\mathrm{K}_{\mathrm{G}-\mathrm{TPU}}\left(163^{\circ} \mathrm{C}\right)$.

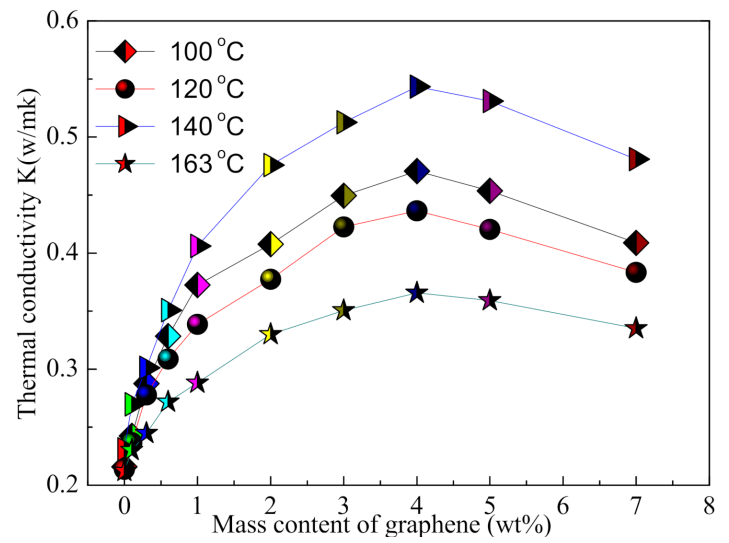

Figure 7. Relationship between the mass content of graphene in the G-TPU film and the thermal conductivities of the pure TPU and the G-TPU composite films with the melting points of TPU of $100{ }^{\circ} \mathrm{C}, 120^{\circ} \mathrm{C}, 140^{\circ} \mathrm{C}$, and $163^{\circ} \mathrm{C}$, respectively.

\subsection{Infrared Light Thermal Response Performances of G-TPU Films}

Further, we studied the infrared (IR) light thermal response performances of G-TPU films prepared from TPU with different melting points. For the IR light thermal response experiment, we irradiated the samples with an IR lamp (light intensity of $5 \times 10^{-4} \mathrm{~W} \cdot \mathrm{cm}^{-2}$ ). Figure 8a shows the relationship of the temperature of the G-TPU composite films prepared by melting point of TPU of $140^{\circ} \mathrm{C}$ and with different mass contents of graphene under the operation of IR lamp. The IR lamp was turned on for $60 \mathrm{~s}$ and turned off. We also measured the G-TPU composite films prepared from the melting point of TPU of $100{ }^{\circ} \mathrm{C}, 140{ }^{\circ} \mathrm{C}$, and $163{ }^{\circ} \mathrm{C}$ with the different mass contents of graphene, respectively (Figures S1-S3). Figure 8b shows the relationship of maximum temperature of the G-TPU composite film prepared by TPU with different melting points and the mass contents of graphene. The insets in Figure $8 \mathrm{~b}$ show photos of the tested sample and samples at maximum temperature.
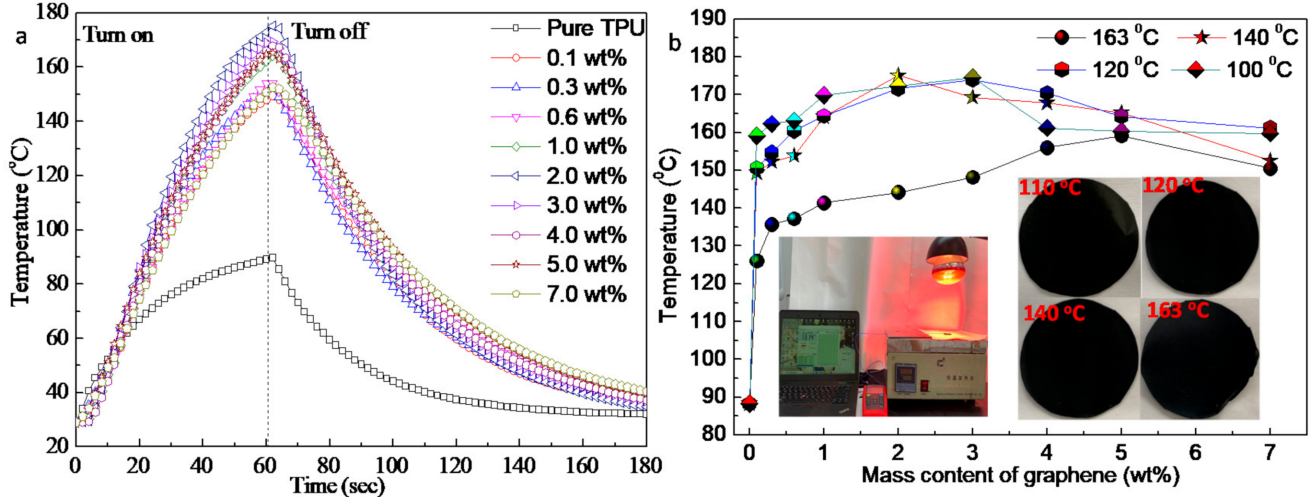

Figure 8. (a) Relationship of the temperature of the G-TPU composite films prepared from melting point TPU of $140{ }^{\circ} \mathrm{C}$ and with different mass contents of graphene under the operation of IR lamp, and (b) the maximum temperature of the G-TPU composite films prepared from TPU with different melting points and the mass content of graphene. The insets are photos of the tested sample and samples at maximum temperature.

As seen from Figure 8, same as our previous research results, when graphene sheets were added into TPU, the temperature of the G-TPU composite films increase significantly 
under IR irradiation, indicating that the composite films have obvious IR irradiation response characteristics. With the increase of graphene mass content, the temperatures of the composite film first increase and then decrease, except that the temperature of the composite film prepared from TPU with a melting point of $163{ }^{\circ} \mathrm{C}$ increases with the increase of graphene mass content. The temperature of the pure TPU film heated for $60 \mathrm{~s}$ reached $89.6^{\circ} \mathrm{C}$, while, the temperature of G-TPU composite films with the mass content of graphene of $0.1 \mathrm{wt} \%$ and $2 \mathrm{wt} \%$ reached $161.8^{\circ} \mathrm{C}$ and $175.6^{\circ} \mathrm{C}$, increasing by 1.80 times and 1.96 times, respectively. Although the temperatures of the composite films were far beyond the melting point of pure TPU, no melting of the samples is observed (see the photos of samples at maximum temperature in Figure $8 b$ ). The above experimental results show that graphene not only promotes the IR irradiation thermal effect of the composite film, but also significantly improves the heat resistance of TPU. There is little difference in the temperatures between the composite films prepared by TPU with melting a point of $100{ }^{\circ} \mathrm{C}$, $120^{\circ} \mathrm{C}$, and $140{ }^{\circ} \mathrm{C}$, respectively. However, when the mass content of graphene is less than $5 \mathrm{wt} \%$, the temperature of the composite film prepared from TPU with a melting point of $163{ }^{\circ} \mathrm{C}$ is obviously lower than that of the other three composite films. The possible reason for this phenomenon is related to the structure characteristics of TPU. The morphologies of TPU include hard and soft segments. TPU with a melting point of $163{ }^{\circ} \mathrm{C}$ has a higher hard segment content, which affects the heat transfer of graphene. Figure 9 displays the IR images of the G-TPU films heated for $60 \mathrm{~s}$ by IR irradiation. The IR images show that the distribution of heat conduction channels formed by graphene sheets is uniform compared with the microstructures of G-TPU films in Figures 4 and 5. It can be seen that a certain amount of graphene sheets agglomeration has little effect on the distribution of the electrical conductivity and heat conduction channels formed by graphene sheets.

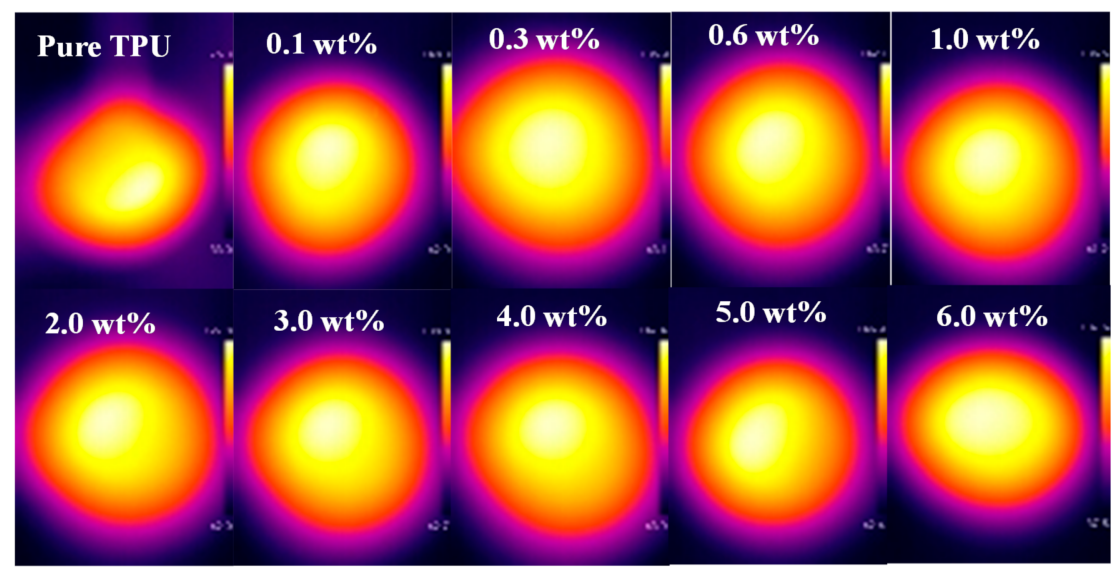

Figure 9. Infrared images of the pure TPU and G-TPU films with different mass contents of graphene sheets.

\section{Conclusions}

Graphene-thermoplastic polyurethane (G-TPU) composite films were fabricated by traditional blending method and tape casting process with commercial graphene sheets as functional fillers and TPU masterbatches of four different melting points as matrix, respectively. The experimental results show that the characteristics of TPU has little influence on the electrical conductivity of the G-TPU composite films prepared with TPU masterbatches of four different melting points, respectively. However, the thermal conductivity of four G-TPU composite films with different melting points is significantly different in the condition of the same mass content of graphene. When the graphene mass content in G-TPU film is $4 \mathrm{wt} \%$, the thermal conductivities of the four G-TPU films reach the maximum, which are $0.4365 \mathrm{~W} \cdot \mathrm{m}^{-1} \cdot \mathrm{K}^{-1}, 0.4706 \mathrm{~W} \cdot \mathrm{m}^{-1} \cdot \mathrm{K}^{-1}, 0.5434 \mathrm{~W} \cdot \mathrm{m}^{-1} \cdot \mathrm{K}^{-1}$, and $0.3657 \mathrm{~W} \cdot \mathrm{m}^{-1} \cdot \mathrm{K}^{-1}$, increasing by a factor of $2.04,2.04,2.56,1.69$, respectively. The four G-TPU composite films have obvious infrared (IR) thermal effect. The temperature of 
G-TPU composite films with the mass content of graphene of $0.1 \mathrm{wt} \%$ and $2 \mathrm{wt} \%$ reach $161.8^{\circ} \mathrm{C}$ and $175.6^{\circ} \mathrm{C}$, increasing by 1.80 times and 1.96 times, respectively. There is little difference in the temperatures between the composite films prepared by TPU with melting a point of $100{ }^{\circ} \mathrm{C}, 120^{\circ} \mathrm{C}$, and $140{ }^{\circ} \mathrm{C}$, respectively; however, when the content of graphene is less than $5 \mathrm{wt} \%$, the temperature of the composite film prepared by TPU with a melting point of $163{ }^{\circ} \mathrm{C}$ is obviously lower than that of the other three composite films. The possible reason for this phenomenon is related to the structure of TPU.

Supplementary Materials: The following are available online at https:/ / www.mdpi.com/2072-666 X/12/2/129/s1, Figure S1: Relationship of the temperature of the G-TPU composite films prepared by melting point TPU of $100{ }^{\circ} \mathrm{C}$ and different mass contents of graphene under the operation of IR lamp; Figure S2: Relationship of the temperature of the G-TPU composite films prepared by melting point TPU of $100{ }^{\circ} \mathrm{C}$ and different mass contents of graphene under the operation of IR lamp; Figure S3: Relationship of the temperature of the G-TPU composite films prepared by melting point TPU of $163^{\circ} \mathrm{C}$ and different mass contents of graphene under the operation of IR lamp.

Author Contributions: Z.-M.Z. conceived and designed the experiments and investigation; K.W. and K.-w.L. performed the experiments and analyzed the data; Y.-H.W. and J.-Z.L. contributed reagents/materials/analysis tools; Z.-M.Z. and Y.-H.W. conducted the original draft preparation. Y.-H.W. conducted the review and editing. All authors have read and agreed to the published version of the manuscript.

Funding: This work was financially supported by Key fields of ordinary universities of Guangdong Province and Zhongshan Science and Technology Projects (2018SYF10).

Conflicts of Interest: The authors declare no conflict of interest.

\section{References}

1. Li, J.; Liu, Q.; Ho, D.; Zhao, S.; Wu, S.; Ling, L.; Han, F.; Wu, X.; Zhang, G.; Sun, R.; et al. Three-Dimensional Graphene Structure for Healable Flexible Electronics Based on Diels-Alder Chemistry. ACS Appl. Mater. Interfaces 2018, 10, 9727-9735. [CrossRef] [PubMed]

2. Li, J.; Liang, J.; Li, L.; Ren, F.; Hu, W.; Li, J.; Qi, S.; Pei, Q. Healable Capacitive Touch Screen Sensors Based on Transparent Composite Electrodes Comprising Silver Nanowires and a Furan/Maleimide Diels-Alder Cycloaddition Polymer. ACS Nano 2014, 8, 12874-12882. [CrossRef] [PubMed]

3. Huang, Y.; Zhu, M.; Meng, W.; Pei, Z.; Liu, C.; Chunyi, Z.; Zhi, C. Magnetic-Assisted, Self-Healable, Yarn-Based Supercapacitor. ACS Nano 2015, 9, 6242-6251. [CrossRef] [PubMed]

4. Terryn, S.; Brancart, J.; Lefeber, D.; Van Assche, G.; VanderBorght, B. A Pneumatic Artificial Muscle Manufactured Out of Self-Healing Polymers That Can Repair Macroscopic Damages. IEEE Robot. Autom. Lett. 2017, 3, 16-21. [CrossRef]

5. Bandodkar, A.J.; López, C.S.; Mohan, A.M.V.; Yin, L.; Kumar, R.; Wang, J. All-printed magnetically self-healing electrochemical devices. Sci. Adv. 2016, 2, e1601465. [CrossRef] [PubMed]

6. Oh, C.-R.; Lee, S.H.; Park, J.-H.; Lee, D.-S. Thermally Self-Healing Graphene-Nanoplate/Polyurethane Nanocomposites via Diels-Alder Reaction through a One-Shot Process. Nanomaterials 2019, 9, 434. [CrossRef]

7. Bonab, V.S.; Karimkhani, V.; Manas-Zloczower, I. Ultra-Fast Microwave Assisted Self-Healing of Covalent Adaptive Polyurethane Networks with Carbon Nanotubes. Macromol. Mater. Eng. 2019, 304, 1800405. [CrossRef]

8. Zeng, Z.; Chen, M.; Pei, Y.; Shahabadi, S.I.S.; Che, B.; Wang, P.; Lu, X. Ultralight and Flexible Polyurethane/Silver Nanowire Nanocomposites with Unidirectional Pores for Highly Effective Electromagnetic Shielding. ACS Appl. Mater. Interfaces 2017, 9 , 32211-32219. [CrossRef]

9. Gul, M.; Jelani, M.; Hassan, N.U.; Naeem, M.; Rakha, S.A.; Khurram, A.A.; Ali, N.; Munir, A. Modified electrical and microwave absorption properties of silver nanowires grown on graphene nanoplatelets. Mater. Res. Express 2019, 6, 1250f8. [CrossRef]

10. Lee, W.; Kihm, K.D.; Lee, W.; Won, P.; Han, S.; Lim, G.; Pyun, K.R.; Ko, S.H. Boosted thermal conductance of polycrystalline graphene by spin-coated silver nanowires. Int. J. Heat Mass Transf. 2019, 134, 547-553. [CrossRef]

11. Jing, X.; Mi, H.-Y.; Peng, X.-F.; Turng, L.-S. Biocompatible, self-healing, highly stretchable polyacrylic acid/reduced graphene oxide nanocomposite hydrogel sensors via mussel-inspired chemistry. Carbon 2018, 136, 63-72. [CrossRef]

12. Wang, Y.; Liu, Q.; Li, J.; Ling, L.; Zhang, G.; Sun, R.; Wong, C.-P. UV-triggered self-healing polyurethane with enhanced stretchability and elasticity. Polymer 2019, 172, 187-195. [CrossRef]

13. Cheng, H.; Huang, Y.; Cheng, Q.; Shi, G.; Jiang, L.; Qu, L.-T. Self-Healing Graphene Oxide Based Functional Architectures Triggered by Moisture. Adv. Funct. Mater. 2017, 27, 27. [CrossRef]

14. Huang, J.; Cao, L.; Yuan, D.; Chen, Y. Design of Novel Self-Healing Thermoplastic Vulcanizates Utilizing Thermal/Magnetic/LightTriggered Shape Memory Effects. ACS Appl. Mater. Interfaces 2018, 10, 40996-41002. [CrossRef] [PubMed] 
15. Jiang, D.; Wang, Y.; Li, B.; Sun, C.; Wu, Z.; Yan, H.; Xing, L.; Qi, S.; Li, Y.; Liu, H.; et al. Flexible Sandwich Structural Strain Sensor Based on Silver Nanowires Decorated with Self-Healing Substrate. Macromol. Mater. Eng. 2019, 304. [CrossRef]

16. Guillame, S.M.; Khalil, H.; Misra, M. Green and sustainable polyurethanes for advanced applications. J. Appl. Polym. Sci. 2017, 134, 45646. [CrossRef]

17. Luan, Y.; Gao, F.; Li, Y.; Yang, J.; Hu, Y.; Guo, Z.; Wang, Z.; Zhou, A. Healing mechanisms induced by synergy of Graphene-CNTs and microwave focusing effect for the thermoplastic polyurethane composites. Compos. Part A Appl. Sci. Manuf. 2018, $106,34-41$. [CrossRef]

18. Huang, L.; Yi, N.; Wu, Y.; Zhang, Y.; Zhang, Q.; Huang, Y.; Ma, Y.; Chen, Y. Multichannel and Repeatable Self-Healing of Mechanical Enhanced Graphene-Thermoplastic Polyurethane Composites. Adv. Mater. 2013, 25, 2224-2228. [CrossRef]

19. Szmechtyk, T.; Sienkiewicz, N.; Woźniak, J.; Strzelec, K. Polyurethanes as self-healing materials. Curr. Chem. Lett. 2015, 4, 61-66. [CrossRef]

20. Lin, S.-C.; Ma, C.-C.M.; Liao, W.-H.; Wang, J.-A.; Zeng, S.-J.; Hsu, S.-Y.; Chen, Y.-H.; Hsiao, S.-T.; Cheng, T.-Y.; Lin, C.-W.; et al. Preparation of a graphene-silver nanowire hybrid/silicone rubber composite for thermal interface materials. J. Taiwan Inst. Chem. Eng. 2016, 68, 396-406. [CrossRef]

21. Xiang, Z.; Zhang, L.; Ling, Z.; Yuan, T.; Zhang, W.; Sun, J. Reduced Graphene Oxide-Reinforced Polymeric Films with Excellent Mechanical Robustness and Rapid and Highly Efficient Healing Properties. ACS Nano 2017, 11, 7134-7141. [CrossRef] [PubMed]

22. Cataldi, P.; Ceseracciu, L.; Athanassiou, A.; Bayer, I.S. Healable Cotton-Graphene Nanocomposite Conductor for Wearable Electronics. ACS Appl. Mater. Interfaces 2017, 9, 13825-13830. [CrossRef] [PubMed]

23. Roy, S.; Srivastava, S.K.; Pionteck, J.; Mittal, V. Mechanically and Thermally Enhanced Multiwalled Carbon Nanotube-Graphene Hybrid filled Thermoplastic Polyurethane Nanocomposites. Macromol. Mater. Eng. 2014, 300, 346-357. [CrossRef]

24. Strankowski, M.; Piszczyk, Ł.; Kosmela, P.; Korzeniewski, P. Morphology and the physical and thermal properties of thermoplastic polyurethane reinforced with thermally reduced graphene oxide. Pol. J. Chem. Technol. 2015, 17, 88-94. [CrossRef]

25. Wang, K.; Zhou, Z.; Zhang, J.; Tang, J.; Wu, P.; Wang, Y.; Zhao, Y.; Leng, Y. Electrical and Thermal and Self-Healing Properties of Graphene-Thermopolyurethane Flexible Conductive Films. Nanomaterials 2020, 10, 753. [CrossRef]

26. Wang, Y.; Zhou, Z.; Zhang, J.; Tang, J.; Wu, P.; Wang, K.; Zhao, Y. Properties of Graphene-Thermoplastic Polyurethane Flexible Conductive Film. Coatings 2020, 10, 400. [CrossRef]

27. Yang, L.; Lu, X.; Wang, Z.; Xia, H. Diels-Alder dynamic crosslinked polyurethane/polydopamine composites with NIR triggered self-healing function. Polym. Chem. 2018, 9, 2166-2172. [CrossRef]

28. Li, Y.; Chen, S.; Wu, M.; Sun, J. Rapid and Efficient Multiple Healing of Flexible Conductive Films by Near-Infrared Light Irradiation. ACS Appl. Mater. Interfaces 2014, 6, 16409-16415. [CrossRef]

29. Wang, Z.; Yang, Y.; Burtovyy, R.; Luzinov, I.; Urban, M.W. UV-induced self-repairing polydimethylsiloxane-polyurethane (PDMS-PUR) and polyethylene glycol-polyurethane (PEG-PUR) Cu-catalyzed networks. J. Mater. Chem. A 2014, 2, 15527-15534. [CrossRef] 